\title{
ANALISIS FAKTOR-FAKTOR YANG MEMPENGARUHI KEPUTUSAN PETANI MELAKUKAN KONVERSI LAHAN SAWAH DAN \\ DAMPAKNYA TERHADAP PENDAPATAN PETANI (Studi Kasus Konversi Lahan Sawah di Kecamatan Kaliwates Kabupaten Jember)
}

\author{
ANALYSIS OF FACTORS AFFECTING DECISIONS FARMERS ARE \\ CONVERSING LAND AND FISHINGS IMPACT ON FARMERS 'REVENUES \\ (Case Study of Wetland Rice Conversion in Kecamatan Kaliwates Kabupaten Jember) \\ Yuanita Ayu Wulandari ${ }^{1)}$, Rudi Hartadi ${ }^{2}$ \& Aryo Fajar Sunartomo ${ }^{3)}$ \\ 1)Mahasiswa Program Studi Agribisnis Fakultas Pertanian Universitas Jember \\ 2)Program Studi Agribisnis Fakultas Pertanian Universitas Jember \\ email:yuanitawulan01@gmail.com
}

\begin{abstract}
This study aimed to know: (1) the rate of rice field conversion in Kaliwates Sub-district Jember Regency; (2) factors affecting the farmer's decision to convert rice field in Kaliwates subdistrict Jember Regency; (3) the impact of rice field conversion on farmers' income in Kaliwates Sub-district, Jember Regency. The research was conducted in Kaliwates sub-district, Jember District. The used research methods were descriptive and analytical. The data were analyzed by using conversion rate, logistic regression, and t test of average difference. The used sampling method was proportionated stratified random sampling. The used data collection method was interview. The analysis results indicated that: (1) the rate of rice field conversion showed the shrinking of rice fieldsin Kaliwates sub-district of Jember Regency. The rate of rice field conversion during the period of 2006-2015 in Kaliwates Sub-district Jember Regency was 4,359\% or 38,48 ha per year. (2) The factors influencing the farmers' decision to convert rice field in Kaliwates sub-district of Jember Regency were land price, number of family dependent, and irrigation water channel. (3) The impact of rice field conversion on farmers' income in Kaliwates sub-district of Jember Regency wasthat there was no significant difference of income between farmer before and after converting rice field. The average farmers' total income before and after converting rice fields changed from Rp. 3,888,520 to Rp. 4.367.397.
\end{abstract}

Keywords: Conversion, Rice Field, Conversion Factors, Income 


\section{PENDAHULUAN}

Pertanian secara garis besar dapat diartikan sebagai (a) proses produksi; (2) petani atau pengusaha; (3) tanah tempat usaha atau lahan pertanian; dan (4) usaha pertanian (Soetriono et al., 2006). Lahan pertanian merupakan faktor produksi yang memiliki fungsi strategis bagi masyarakat Indonesia. Seiring dengan meningkatnya kebutuhan lahan, ketersediaan lahan terutama lahan pertanian yang relatif tetap menjadi semakin terancam. Alih fungsi lahan atau konversi lahan pertanian pada intinya terjadi akibat adanya persaingan dalam pemanfaatan lahan antara sektor pertanian dan sektor non pertanian (Irawan, 2008).

Secara empiris lahan pertanian yang paling rentan terhadap konversi adalah lahan sawah. Provinsi Jawa Timur adalah salah satu daerah yang memberikan sumbangan produksi padi terhadap tanaman pangan terbesar yaitu mencapai lebih dari 50 persen. Hal ini menunjukkan bahwa Provinsi Jawa Timur berperan besar dalam memasok produk pertanian bagi kebutuhan Nasional. Namun, gencarnya pengembangan usaha pada sektor sekunder dan tersier sebagai akibat dari perkembangan perekonomian menyebabkan luas lahan pertanian dari tahun ke tahun terus mengalami penurunan (BPS, 2015). Berdasarkan penelitian Hidayat (2008), wilayah Jember merupakan salah satu wilayah yang paling dominan mengalami konversi lahan sawah. Kabupaten Jember merupakan salah satu Lumbung Pangan yang dimiliki Jawa Timur dengan kontribusi produksi padi terbesar kelima di Jawa Timur. Kaliwates merupakan salah satu Kecamatan di Kabupaten Jember yang mengalami pertumbuhan cukup besar pada kawasan real estates/perumahan sehingga keberadaan lahan pertanian terutama lahan sawah menjadi semakin terancam.

Tabel 1. Perkembangan Luasan Lahan (ha) untuk Perumahan di Kecamatan Kaliwates Kabupaten Jember Tahun 2011-2015

\begin{tabular}{ll}
\hline Tahun & Perumahan \\
\hline 2011 & $1.528,34$ \\
2012 & $1.550,96$ \\
2013 & $1.627,85$ \\
2014 & $1.661,88$ \\
2015 & $1.672,42$ \\
\hline
\end{tabular}

Sumber : Badan Pertanahan Nasional Kabupaten Jember, 2016 (diolah)

Pembangunan kawasanreal estate/perumahan di wilayah tersebut memberikan dampak terhadap lingkungan. Kondisi air untuk pengairan di lahan persawahan Kecamatan Kaliwates dirasa semakin sulit. Hal ini disebabkan areal persawahan sebagai tempat resapan air semakin berkurang dan terkendalanya ketersediaan air irigasi di persawahan milik petani. Sehingga beberapa petani mempertimbangkan hal tersebut untuk mengambil keputusan terhadap lahan sawah yang dimilikinya. Selain karena pertumbuhan pembangunan real estate/perumahan, konversi lahan juga dipengaruhi oleh faktor lain seperti petani yang menjual lahan sawah karena tergiur dengan harga lahan di kota yang lebih tinggi jika dibandingkan dengan di desa. Fenomena ini berdampak terhadap masyarakat yang bermata pencaharian petani, 
mereka harus mencari atau memilih mata pencaharian baik tetap di sektor pertanian maupun di luar sektor pertanian. Saat ini, petani yang telah melakukan konversi lahan sawah ada yang berwirausaha membuka pertokoan, berdagang, dan lain sebagainya.

Selain itu ada yang tetap bermata pencaharian di bidang pertanian namun di luar wilayah Kecamatan Kaliwates.

Berdasarkan pada latar belakang permasalahan tersebut penelitian ini bertujuan untuk mengetahui laju konversi lahan sawah dan faktor yang mempengaruhi keputusan petani melakukan konversi lahan sawah. Selain itu, penelitian ini juga dilakukan untuk mengetahui dampak konversi lahan sawah terhadap pendapatan petani. Hipotesis tujuan pertama pada penelitian ini adalah laju konversi lahan sawah mengalami penyusutan. Hipotesis kedua penelitian ini adalah faktor yang mempengaruhi keputusan petani melakukan konversi lahan sawah adalah harga lahan, tingkat usia, lama pendidikan, luas lahan, proporsi pendapatan sektor pertanian, tanggungan keluarga, pengalaman bertani, saluran irigasi, dan pengetahuan petani tentang peraturan konversi lahan sawah. Hipotesis tujuan ketiga tentang dampak konversi lahan sawah terhadap pendapatan petani adalah terdapat perbedaan pendapatan.

\section{METODE PENELITIAN}

Penentuan daerah penelitian dilakukan secara purposive method, artinya dipilih berdasarkan pada pertimbangan tertentu. Dipilihnya Kecamatan Kaliwates sebagai daerah penelitian didasarkan karena wilayah tersebut merupakan wilayah yang banyak mengalami konversi lahan sawah. Kecamatan Kaliwates sebagian besar dijadikan sebagai kawasan perumahan.

Metode penelitian yang digunakan dalam penelitian ini adalah metode deskriptif dan metode analitis. Tujuan dari penelitian deskriptif ini adalah membuat deskripsi, gambaran, atau lukisan secara sistematis, faktual dan akurat mengenai terjadinya konversi lahan sawah di Kecamatan Kaliwates. Metode analitis digunakan untuk mengetahui laju konversi lahan sawah di Kecamatan Kaliwates, mengetahui faktorfaktor yang mempengaruhi pengambilan keputusan petani melakukan konversi lahan sawah dan dampak konversi lahan sawah terhadap pendapatan petani di Kecamatan Kaliwates Kabupaten Jember.

Metode pengambilan contoh yang digunakan dalam penelitian ini adalah metode Proportionated Sratified Random Sampling. Sampel yang dijadikan sebagai responden adalah 93 petani. Sampel tersebut terbagi menjadi dua jenis yaitu 29 petani yang telah melakukan konversi lahan sawah dan 64 petani yang tidak melakukan konversi lahan sawah.

Metode pengumpulan data untuk memperoleh data primer dilakukan dengan wawancara secara langsung dengan petani yang telah melakukan konversi lahan sawah dan petani yang tidak melakukan konversi lahan sawah. Wawancara dilakukan secara terstruktur dan melalui tatap muka (face to face) terhadap responden berdasarkan daftar 
pertanyaan. Sedangkan untuk memperoleh data sekunder dilakukan dengan cara mencari data dari berbagai instansi pemerintah atau lembaga terkait, serta dari literatur yang berhubungan dengan penelitian ini.

Untuk menguji hipotesis pertama mengenai laju konversi lahan digunakan analisis laju alih fungsi lahan. Menurut Sutandi (2009) dalam Agustina dan Robbinov (2016) laju alih fungsi lahan dapat ditentukan dengan cara menghitung laju penyusutan lahan secara parsial. Laju penyusutan lahan secara parsial dapat dijelaskan sebagai berikut :

$$
V=\frac{\mathrm{Lt}-\mathrm{Lt}-1}{\mathrm{Lt}-1} \times 100 \%
$$

Laju alih fungsi lahan dapat diketahui melalui selisih antara luas tahun ke$\mathrm{t}$ dengan luas lahan tahun sebelum $\mathrm{t}(\mathrm{t}-1)$ dan dikalikan dengan 100 persen. Kriteria pengambilan keputusan adalah nilai $\mathrm{V}<0$ berarti bahwa luas lahan tersebut mengalami penyusutan.

Untuk menguji hipotesis kedua mengenai faktor yang mempengaruhi keputusan petani melakukan konversi lahan sawah digunakan analisis regresi logistik atau sering disebut dengan model logit. Berikut adalah formulasi persamaan model regresi logistik (Gani dan Amalia, 2015):Y= $\ln \left(\frac{p}{1-p}\right)=\beta_{0}+\beta_{1} x_{1}+\beta_{2} x_{2}+\beta_{3} x_{3}+$ $\beta_{4} x_{4}+\beta_{5} x_{5}+\beta_{6} x_{6}+\beta_{7} x_{7}+$ $\beta_{8} x_{8}+\beta_{9} x_{9}+e_{i}$

Untuk mengetahui pengaruh dari variabel independen dapat dilakukan uji signifikansi secara keseluruhan dan secara individu sebagai berikut:

1. Uji Signifikansi secara Keseluruhan

Nilai $G$ pada uji $G$ dengan formulasi sebagai berikut :

$$
\mathrm{G}=-2 \ln \left(\frac{\operatorname{likelihood}(\text { Model } B)}{\text { likelihood }(\text { Model } A)}\right)
$$

Kriteria pengambilan keputusan:

a. H0 ditolak jika $\mathrm{G}>\gamma^{2}$; model dengan variabel bebas signifikan pada tingkat signifikansi $5 \%$.

b. H0 diterima jika $\mathrm{G} \leq \gamma^{2}$; model dengan variabel bebas tidak signifikan pada tingkat signifikansi 5\%.

2. Uji Signifikansi secara Individual

Nilai Wald pada uji W (wald) diperoleh dengan menggunakan rumus :

$$
W i=\left[\frac{\widehat{\beta}_{l}}{\operatorname{Se} \widehat{\beta}_{l}}\right]^{2}
$$

Kriteria Pengambilan Keputusan :

a. $\quad W i>Z_{\alpha / 1}$ atau probabilitas (signifikansi) $<0,05$, maka variabel bebas secara individu berpengaruh nyata terhadap keputusan petani melakukan konversi lahan sawah.

b. $\quad W i \leq Z_{\alpha / 1}$ atau probabilitas (signifikansi) $>0,05$, maka variabel independen secara individu tidak berpengaruh nyata terhadap keputusan petani melakukan konversi lahan sawah.

Untuk menguji hipotesis ketiga mengenai dampak konversi lahan sawah terhadap pendapatan petani digunakan uji 
beda atau distribusi $t$-test. Rumus uji t adalah sebagai berikut (Sugiyono, 2014) :

to $=\frac{\bar{X}_{1}-\bar{X}_{2}}{\sqrt{\frac{s_{1}^{2}}{n_{1}}+\frac{s_{2}^{2}}{n_{2}}-2 r \frac{s_{1}}{\sqrt{n_{1}}}+\frac{s_{2}}{\sqrt{n_{2}}}}}$

Kriteria pengambilan keputusan:

a. $\quad \mathrm{t}_{0}>\mathrm{t}$ tabel atau probabilitas $\mathrm{t}$ hitung < 0,05, artinya terdapat perbedaan pendapatan petani sebelum dan sesudah konversi lahan sawah (rata-rata pendapatan petani sebelum dan sesudah konversi lahan sawah adalah tidak sama/berbeda nyata).

a. $\quad \mathrm{t}_{0} \leq \mathrm{t}$ tabel atau probabilitas $\mathrm{t}$ hitung $>$ 0,05 , artinya tidak terdapat perbedaan pendapatan petani sebelum dan sesudah konversi lahan sawah (rata-rata pendapatan petani sebelum dan sesudah konversi lahan sawah adalah sama/tidak berbeda nyata).

\section{HASIL DAN PEMBAHASAN}

\section{Laju Konversi Lahan Sawah di Kecamatan Kaliwates Kabupaten Jember}

Penggunaan lahan di Kecamatan Kaliwates Kabupaten Jember mengalami perubahan hampir setiap tahun terutama pada lahan sawah. Penggunaan lahan tersebut diubah menjadi perumahan, fasilitas \& jasa, serta penggunaan lahan untuk lainnya. Laju konversi lahan sawah di Kecamatan Kaliwates Kabupaten Jember dianalisis dengan menggunakan perhitungan laju konversi secara parsial. Laju secara parsial merupakan analisis yang memperlihatkan perubahan penggunaan lahan dari tahun ke tahun dimana perubahan tersebut mengacu pada penggunaan lahan di tahun sebelumnya. Laju konversi lahan sawah pada tahun 2006 sampai tahun 2015 dapat diihat pada Tabel 2. berikut ini.

Tabel 2. Konversi dan Laju Konversi Lahan Sawah di Kecamatan Kaliwates Kabupaten Jember Tahun 2006-2015

\begin{tabular}{lll}
\hline Tahun & Konversi Lahan Sawah (Ha) & Laju Konversi Lahan Sawah (\%) \\
\hline 2006 & $-91,33$ & $-9,398$ \\
2007 & $-39,47$ & $-4,483$ \\
2008 & $-6,80$ & $-0,808$ \\
2009 & $-4,27$ & $-0,511$ \\
2010 & $-14,53$ & $-1,750$ \\
2011 & $-39,29$ & $-4,818$ \\
2012 & $-22,60$ & $-2,912$ \\
2013 & $-89,57$ & $-11,888$ \\
2014 & $-36,00$ & $-5,423$ \\
2015 & $-11,7$ & $-1,778$ \\
\hline Rerata & $\mathbf{- 3 8 , 4 8}$ & $\mathbf{- 4 , 3 7 6 9}$ \\
Sumber : Data Primer, 2016(diolah) & tersebut menunjukkan bahwa dalam kurun \\
\multicolumn{2}{c}{ Berdasarkan Tabel 2 nilai laju } & waktu 2006-2015 di Kecamatan Kaliwates \\
konversi lahan sawah yang bertanda negatif & terjadi penyusutan lahan sawah seluas 38,48 \\
menggambarkan adanya penyusutan lahan & hektar per tahun. Rata-rata laju konversi \\
sawah akibat konversi lahan. Pada tabel &
\end{tabular}


lahan sawah adalah sebesar $-4,3769$ persen setiap tahun. Nilai laju konversi lahan $\mathrm{V}<0$, maka berdasarkan kriteria pengambilan keputusan mengidentifikasikan bahwaterjadi penyusutan lahan sawah di Kecamatan Kaliwates Kabupaten Jember. Laju konversi lahan sawah tertinggi terjadi pada tahun 2013 yang mengalami kenaikan menjadi sebesar 11,88 persen. Sedangkan laju konversi lahan sawah terendah terjadi pada tahun 2009 yaitu sebesar -0,511 persen.

\section{Faktor-faktor yang Mempengaruhi Keputusan Petani Melakukan Konversi Lahan Sawah di Kecamatan Kaliwates}

Analisis yang digunakan untuk mengetahui faktor-faktor yang berpengaruh terhadap keputusan petani melakukan konversi lahan sawah di Kecamatan Kaliwates adalah analisis regresi logistik. Terdapat sembilan faktor yang diduga berpengaruh secara signifikan terhadap keputusan petani melakukan konversi lahan sawah di Kecamatan Kaliwates. Faktorfaktor yang diduga mempengaruhi keputusan petani dalam melakukan konversi lahan sawah di Kecamatan Kaliwates adalah 1) harga lahan sawah, 2) usia petani, 3) lama pendidikan petani,
4) luas lahan petani, 5) proporsi pendapatan sektor pertanian, 6) jumlah keluarga yang ditanggung petani, 7) pengalaman petani, 8) saluran irigasi, dan 9) pengetahuan petani tentang peraturan konversi lahan.

Faktor yang signifikan diidentifikasi dengan melihat nilai signifikansi pengaruh variabel bebas secara bersama-sama dan secara individu terhadap variabel terikat. Pengujian terhadap adanya pengaruh sembilan variabel bebas ini dilakukan dengan melihat nilai signifikansi chi-square yang diperoleh dari uji Omnibus Tests of Model Coefficients, apabila signifikansi chi-square $<5 \%$ maka dapat disimpulkan bahwa kesembilan variabel bebas secara signifikan berpengaruh terhadap peluang petani melakukan konversi lahan sawah, nilai ini juga menunjukkan goodness of fit dari model yang disusun. Pengaruh variabel bebas secara individu pada penelitian ini dikatakan signifikan apabila nilai signifikansi $<5 \%$, hasil ini bisa diketahui dari nilai signifikansi Uji Wald.Adanya pengaruh variabel bebas secara bersama-sama tersebut dalam hasil analisis regresi logistik ditunjukkan pada Tabel 3.

Tabel 3. Hasil Analisis Regresi untuk Goodness Of Fit Model secara Keseluruhan

\begin{tabular}{|c|c|c|c|}
\hline Uji & Hasil & & Keterangan \\
\hline \multirow{2}{*}{$\begin{array}{l}\text { Omnibus Tests of Model } \\
\text { Coefficients }\end{array}$} & Chi-square & Signifikansi & \multirow{2}{*}{$\begin{array}{l}\text { Berpengaruh } \\
\text { signifikan }\end{array}$} \\
\hline & 60,341 & $0,01 \%$ & \\
\hline \multirow{2}{*}{ Model Summary } & Cox \& Snell R Square & Nagelkerke R Square & \multirow{2}{*}{$\begin{array}{l}\text { Berpengaruh } \\
\text { signifikan }\end{array}$} \\
\hline & $47,7 \%$ & $67,1 \%$ & \\
\hline \multirow{2}{*}{$\begin{array}{l}\text { Hosmer and Lemeshow } \\
\text { Test }\end{array}$} & Chi-Square & Signifikansi & \multirow{2}{*}{ Model Fit } \\
\hline & 14,779 & $6,4 \%$ & \\
\hline Classification Table & $\begin{array}{l}\text { Overall Percentage Correct } \\
88,2 \%\end{array}$ & & Model akurat \\
\hline
\end{tabular}

Sumber : Data Primer, 2016 (diolah) 
Berdasarkan hasil analisis regresi logistik dengan menggunakan metode Enter yang ditunjukkan pada Tabel 3 dapat diketahui bahwa secara keseluruhan model regresi logistik yang dihasilkan dari analisis bisa digunakan untuk memprediksi peluang petani melakukan konversi lahan sawah. Kesimpulan tersebut didapatkan dari hasil analisis regresi logistik dengan beberapa kriteria yang harus dipenuhi oleh hasil regresi logistik agar model bisa digunakan lebih lanjut. Kriteria tersebut antara lain: 1) Overall Test (Omnibus Tests of Model Coefficients), 2) Model Summary, 3) Hosmer and Lemshow, dan 4) Classification Table.

1. Overall Test Model Logit Mengenai

Keputusan Petani Melakukan Konversi

Lahan Sawah

Berdasarkan pada Tabel 5, Nagelkerke $R$ Square menunjukkan nilai yang lebih besar dari 50\% yang artinya variabel bebas bisa menjelaskan variabilitaskeputusan petani melakukan konversi lahan sawah dengan baik. Nilai Cox \& Snell $R$ Square adalah sebesar $47,7 \%$ dan nilai Nagelkerke $R$ Square sebesar 67,1\%. Nilai Nagelkerke $R$ Square lebih besar dari nilai Cox \& Snell $R$ Square artinya variabilitas variabel bebas yaitu harga lahan sawah, usia petani, lama pendidikan petani, luas lahan petani, proporsi pendapatan sektor pertanian, jumlah keluarga yang ditanggung petani, pengalaman petani, saluran irigasi, dan pengetahuan petani tentang peraturan konversi lahan mampu menjelaskan variabilitas keputusan petani melakukan konversi lahan sawah sebesar $67,1 \%$ sedangkan sisanya yakni sebesar $32,9 \%$ dijelaskan oleh variabilitas variabel lain diluar model.

2. Hosmer and Lemeshow Testdari Model Logit Mengenai Keputusan Petani Melakukan Konversi Lahan Sawah

Tabel 4. Omnibus Tests of Model Coefficients Model Logit Mengenai Keputusan Petani Melakukan Konversi Lahan Sawah

\begin{tabular}{lllll}
\hline & Chi-square & Df & \multicolumn{2}{c}{ Sig. } \\
\hline Step 1 & Step & 60,341 & 9 & .000 \\
& Block & 60,341 & 9 & .000 \\
& Model & 60,341 & 9 & .000 \\
\hline
\end{tabular}

Sumber : Data Primer, 2016 (diolah)

Berdasarkan Tabel 4 tersebut, Omnibus Tests of Model Coefficients menunjukkan nilai chisquare sebesar 60,341 dengan signifikansi sebesar $0,01 \%$. Nilai tersebut kurang dari $5 \%$ yang menunjukkan bahwa dengan tingkat kepercayaan 95 persen secara bersama-sama variabel bebas yang dianalisis berpengaruh secara signifikan terhadap peluang petani melakukan konversi lahan sawah. Selain itu bisa dikatakan bahwa ada minimal satu variabel bebas yang berpengaruh pada variabel tidak bebas sehingga dapat diambil kesimpulan model dapat digunakan untuk analisis lebih lanjut. 
Tabel 5.Nagelkerke $R$ Square Model Logit Mengenai Keputusan Petani Melakukan Konversi Lahan Sawah

\begin{tabular}{llll} 
Step & $\mathbf{- 2}$ Log likelihood & Cox \& SnellR Square & Nagelkerke R Square \\
\hline 1 & $55.083(\mathrm{a})$ & .477 & .671 \\
\hline
\end{tabular}

Sumber : Data Primer, 2016 (diolah)

Tabel 6.Hosmer and Lemeshow TestModel Logit Mengenai Keputusan Petani Melakukan Konversi Lahan Sawah

\begin{tabular}{llllll}
\hline Step & Chi-square & Df & Sig. & \\
\hline 1 & & 14.779 & 8 & & .064 \\
\hline
\end{tabular}

Sumber : Data Primer, 2016 (diolah)

Hosmer and Lemeshow Test dinilai fit artinya model regresi layak untuk

menunjukkan bahwa nilai chi-square digunakan dalam analisis selanjutnya atau sebesar14,779 dengan nilai signifikansi cukup mampu menjelaskandata atau sesuai sebesar 6,4\%. Nilai signifikansi $0,064>0,05$ dengan kondisi yang terjadi.

pada taraf kepercayaan 95\%, maka dapat

3. Classification Table dari Model Logit disimpulkan bahwa model yang digunakan Mengenai Keputusan Petani Melakukan adalah sesuai dengan data atau model regresi Konversi Lahan Sawah

Tabel 7. Classification Table Model Logit Mengenai Keputusan Petani Melakukan Konversi Lahan Sawah

\begin{tabular}{|c|c|c|c|c|c|}
\hline & \multirow{3}{*}{ Observed } & & \multicolumn{3}{|l|}{ Predicted } \\
\hline & & & \multicolumn{2}{|c|}{ keputusan_petani } & \multirow{2}{*}{$\begin{array}{l}\begin{array}{l}\text { Percentage } \\
\text { Correct }\end{array} \\
\text { non-konversi }\end{array}$} \\
\hline & & & $\begin{array}{l}\text { non- } \\
\text { konversi }\end{array}$ & konversi & \\
\hline \multirow{3}{*}{ Step 1} & \multirow{2}{*}{ keputusan_petani } & non-konversi & 60 & 4 & 93.8 \\
\hline & & Konversi & 7 & 22 & 75.9 \\
\hline & Overall Percentage & & & & 88.2 \\
\hline
\end{tabular}

Sumber : Data Primer, 2016 (diolah)

Berdasarkan Tabel 7 didapatkan bahwa nilai Overall Percentage sebesar 88,2. Nilai Overall Percentage Correct sebesar $88,2 \%$ yang artinya kemampuan model regresi logistik yang digunakan sudah cukup baik karena mampu menduga ketepatan prediksi pada penelitian atau kondisi yang terjadi di lapang dengan tingkat akurasi sebesar $88,2 \%$. Hal ini menunjukkan bahwa model yang dihasilkan baik.
Secara bersama-sama sembilan faktor yang diduga berpengaruh memiliki pengaruh nyata terhadap keputusan petani melakukan konversi lahan sawah. Tahap selanjutnya adalah mengetahui pengaruh dan besaran pengaruh dari variabel bebas secara individu terhadap keputusan petani melakukan konversi lahan sawah. Nyata atau tidaknya pengaruh diidentifikasi dengan melihat nilai signifikansi uji wald masingmasing variabel bebas pada tabel variables in the equation pada output analisis regresi 
logistik dan besaran pengaruh diidentifikasi dengan melihat nilai odds ratio atau $\operatorname{Exp}(B)$. Selain dua nilai tersebut model hasil analisis dan jenis pengaruh variabel baik yang berpengaruh berbanding lurus atau berbanding terbalik bisa diketahui dengan melihat nilai konstanta masing-masing variabel bebas. Hasil analisis tersebut ditampilkan pada Tabel 8 berikut ini.

Tabel 8. Koefisien, Wald, Signifikansi,dan Odd Ratio Nilai Variabel Bebas

\begin{tabular}{|c|c|c|c|c|c|c|}
\hline Variabel & B & S.E. & Wald & df & Sig. & $\operatorname{Exp}(B)$ \\
\hline Harga lahan $\left(\mathbf{X}_{1}\right)$ & .000 & .000 & 5.685 & 1 & .017 & 1.000 \\
\hline Usia Petani $\left(\mathrm{X}_{2}\right)$ & .058 & .051 & 1.251 & 1 & .263 & 1.059 \\
\hline $\begin{array}{l}\text { Tigkat pendidikan } \\
\text { petani }\left(\mathrm{X}_{3}\right)\end{array}$ & .082 & .099 & .698 & 1 & .404 & 1.086 \\
\hline Luas lahan $\left(\mathrm{X}_{4}\right)$ & .000 & .000 & .059 & 1 & .808 & 1.000 \\
\hline Proporsi pendapatan $\left(\mathrm{X}_{5}\right)$ & -.013 & .014 & .853 & 1 & .356 & .987 \\
\hline $\begin{array}{l}\text { Jumlah tanggungan } \\
\text { keluarga }\left(X_{6}\right)\end{array}$ & 1.066 & .401 & 7.057 & 1 & .008 & 2.903 \\
\hline Pengalaman bertani $\left(\mathrm{X}_{7}\right)$ & -.020 & 037 & .302 & 1 & .583 & .980 \\
\hline $\begin{array}{l}\text { Kendala saluran irigasi } \\
\left(\mathbf{X}_{8}\right)\end{array}$ & 3.607 & .872 & 17.125 & 1 & .000 & 36.856 \\
\hline $\begin{array}{l}\text { Pengetahuan Petani } \\
\text { terkait konversi }\left(\mathrm{X}_{9}\right)\end{array}$ & -2.487 & 2.931 & .720 & 1 & .396 & .083 \\
\hline Konstanta & -4.065 & 2.849 & 2.036 & 1 & .154 & .017 \\
\hline
\end{tabular}

Keterangan $\quad: *)$ Signifikan pada Taraf Kepercayaan 95\%

Sumber : Data Primer, 2016 (diolah)

Variabel bebas yang berpengaruh nyata terhadap keputusan petani melakukan konversi lahan sawah adalah variabel harga lahan, variabel jumlah keluarga yang ditanggung petani, dan variabel kendala saluran irigasi. Taraf nyata yang digunakan pada penelitian ini adalah 5\% sehingga variabel bebas dikatakan berpengaruh nyata apabila memiliki nilai error kurang dari 5\%. Variabel lain yaitu variabel usia petani, tingkat pendidikan petani, luas lahan, proporsi pendapatan, pengalaman petani, dan pengetahuan petani tentang peraturan konversi lahan sawah tidak berpengaruh secara nyata terhadap keputusan petani untuk melakukan konversi lahannya. Model yang diperoleh dari hasil analisis regresi logistik dengan melihat nilai koefisien pada Tabel 8 adalah sebagai berikut:

$$
\begin{aligned}
& \mathrm{Y}=\ln \left(\frac{p}{1-p}\right)=-4,065+0,0001 \mathrm{X}_{1}+ \\
& 0,058 \mathrm{X}_{2} \quad+0,082 \mathrm{X}_{3} \quad+0,0001 \mathrm{X}_{4} \quad- \\
& 0,013 \mathrm{X}_{5}+1,066 \mathrm{X}_{6} \quad-0,020 \mathrm{X}_{7}+ \\
& 3,607 \mathrm{X}_{8}-2.487 \mathrm{X}_{9}
\end{aligned}
$$

Dalam analisis regresi logistik, diperlukan uji asumsi klasik berupa uji multikolinearitas. Apabila diantara variabelvariabel bebas tidak terdapat variabelvariabel bebas yang saling memiliki korelasi yang tinggi, maka dapat disimpulkan bahwa tidak terdapat gangguan multikolinearitas pada model penelitian. Hasil uji multikolinearitas dapat ditampilkan pada Tabel 9 berikut. 
Tabel 9. Uji Asumsi Multikolinieritas dalam Model

\begin{tabular}{|c|c|c|c|c|c|c|c|c|c|c|}
\hline & $\begin{array}{l}\text { Cons } \\
\text { tant }\end{array}$ & $\begin{array}{l}\text { Harg } \\
\mathrm{a} \\
\text { laha } \\
\mathrm{n}\end{array}$ & Usia & $\begin{array}{l}\text { Lama } \\
\text { pendidi } \\
\text { kan }\end{array}$ & $\begin{array}{l}\text { Luas } \\
\text { laha } \\
\mathrm{n}\end{array}$ & $\begin{array}{l}\text { Propors } \\
i \\
\text { pendap } \\
\text { atan }\end{array}$ & $\begin{array}{l}\text { Jumlah } \\
\text { tanggun } \\
\text { gan } \\
\text { keluarg } \\
\text { a } \\
\end{array}$ & $\begin{array}{l}\text { Penga } \\
\text { laman } \\
\text { tani }\end{array}$ & $\begin{array}{l}\text { Iriga } \\
\text { si }\end{array}$ & $\begin{array}{l}\text { Penge } \\
\text { tahuan } \\
\text { petani }\end{array}$ \\
\hline Constant & $\begin{array}{l}1.00 \\
0\end{array}$ & $\begin{array}{l}- \\
.040\end{array}$ & $\begin{array}{l}. \\
.731\end{array}$ & -.371 & .036 & -.213 & -.432 & .335 & $\begin{array}{l}- \\
.241\end{array}$ & .271 \\
\hline $\begin{array}{l}\text { Harga } \\
\text { lahan }\end{array}$ &.- & $\begin{array}{l}1.00 \\
0\end{array}$ & $\begin{array}{l}- \\
.312\end{array}$ & -.404 &.- & .066 & -.323 & .238 & $\begin{array}{l}- \\
.492\end{array}$ & .261 \\
\hline Usia & $-\overline{.} .731$ & - & $\begin{array}{l}1.00 \\
0\end{array}$ & .420 & .167 & -.034 & .221 & -.731 & .258 & -.275 \\
\hline $\begin{array}{l}\text { Lama } \\
\text { pendidik } \\
\text { an }\end{array}$ & $\begin{array}{l}- \\
.371\end{array}$ & $\begin{array}{l}- \\
.404\end{array}$ & .420 & 1.000 & .156 & .143 & -.059 & -.218 & .396 & -.284 \\
\hline $\begin{array}{l}\text { Luas } \\
\text { lahan }\end{array}$ & .036 & -452 & .167 & .156 & $\begin{array}{l}1.00 \\
0\end{array}$ & -.259 & .034 & -.210 & .227 & -.069 \\
\hline $\begin{array}{l}\text { Proporsi } \\
\text { pendapat } \\
\text { an } \\
\text { Jumlah }\end{array}$ & -.213 & .066 & $\begin{array}{l}- \\
.034\end{array}$ & .143 & $\begin{array}{l}- \\
.259\end{array}$ & 1.000 & -.172 & -.065 & $\begin{array}{l}- \\
.171\end{array}$ & -.007 \\
\hline $\begin{array}{l}\text { tanggung } \\
\text { an } \\
\text { keluarga }\end{array}$ & -.432 & $\begin{array}{l}- \\
.323\end{array}$ & .221 & -.059 & .034 & -.172 & 1.000 & -.079 & .247 & -.335 \\
\hline $\begin{array}{l}\text { Pengala } \\
\text { man tani }\end{array}$ & .335 & .238 & $\begin{array}{l}- \\
.731\end{array}$ & -.218 &. & -.065 & -.079 & 1.000 & $\begin{array}{l}- \\
.144\end{array}$ & .145 \\
\hline Irigasi & $\begin{array}{l}- \\
.241\end{array}$ & $\begin{array}{l}- \\
.492\end{array}$ & .258 & .396 & .227 & -.171 & .247 & -.144 & $\begin{array}{l}1.00 \\
0\end{array}$ & -.089 \\
\hline $\begin{array}{l}\text { Pengetah } \\
\text { uan } \\
\text { petani }\end{array}$ & .271 & .261 & -.275 & -.284 & $\begin{array}{l}- \\
.069\end{array}$ & -.007 & -.335 & .145 & $\begin{array}{l}- \\
.089\end{array}$ & 1.000 \\
\hline
\end{tabular}

Sumber : Data Primer, 2016 (diolah)

Berdasarkan Tabel 9 dapat diketahui nilai koefisien korelasi antara variabelvariabel bebas. Apabila nilai koefisien korelasi antara variabel-variabel tersebut < 0,8 maka tidak memuat multikolinearitas. Hal ini berarti tidak terdapat variabelvariabel bebas yang saling memiliki korelasi yang tinggi, maka dapat disimpulkan bahwa tidak terdapat gangguan multikolinearitas pada model penelitian ini.

Pengaruh masing-masing variabel bebas yang signifikan terhadap keputusan petani melakukan konversi lahan sawah di Kecamatan Kaliwates Kabupaten Jember dapat dijelaskan secara terperinci sebagai berikut :

1. Harga Lahan Sawah $\left(\mathrm{X}_{1}\right)$

Harga lahan sawah adalah variabel dugaan dimana harga lahan menunjukkan tingkat harga jual lahan sawah di Kecamatan Kaliwates. Berdasarkan hasil analisis regresi logistik variabel harga lahan $\left(\mathrm{X}_{1}\right)$ memiliki nilai Sig. sebesar 0,017 atau nilai error sebesar $1,7 \%$. Nilai ini menunjukkan bahwa pada taraf kepercayaan sebesar 95\% variabel harga lahan berpengaruh nyata terhadap keputusan petani melakukan konversi lahan sawah. Koefisien hasil yang diperoleh 
bertanda positif $(+0,0001)$ dan nilai odd ratio atau $\operatorname{Exp}(\beta)$ yakni sebesar 1,000. Hal ini berarti jika harga lahan meningkat 1 rupiah maka akan meningkatkan peluang petani untuk melakukan konversi lahan sawah sebesar 1 kali. Dengan kata lain, peluang petani melakukan konversi lahan sawah adalah sebesar 1 kali lebih tinggi dari pada tidak melakukan konversi lahan sawah dengan asumsi variabel lain dalam keadaan konstan.

Lahan sawah merupakan aset bagi petani dan digunakan sebagai sumber pendapatan. Semakin meningkatnya harga lahan sawah terutama pada daerah-daerah perkotaan mendorong terjadinya konversi lahan sawah. Dengan melakukan konversi lahan sawah maka petani akan memperoleh hasil yang besar dari penjualan tersebut. Dengan begitu, pendapatan petani dari hasil penjualan dapat diinvestasikan kembali. Sebagian besar petani yang menjual lahan sawah kemudian membeli lahan sawah baru di luar Kecamatan Kaliwates (daerah pedesaan) yang relatif lebih murah sehingga mendapatkan lahan sawah yang lebih luas dari lahan sebelumnya. Daerah pembelian sawah baru yang sering dituju oleh petani di Kecamatan Kaliwates adalah daerah yang masih berlokasi disekitar wilayah Kecamatan Kaliwates seperti Kecamatan Ajung, Kecamatan Sukorambi, dan Kecamatan Panti. Sebagian petani lainnya menjual lahan sawah, namun menggunakan uang sebagai modal usaha di luar sektor pertanian (usahatani padi) seperti membuka usaha pertokoan dan penanaman komoditas tanaman lainnya, seperti komoditas tanaman pisang. Dengan demikian mereka tidak kehilangan aset dari lahan sawahnya. Sehingga harga jual yang relatif tinggi memiliki kecenderungan petani untuk menjual lahan.

2. Jumlah Tanggungan Keluarga $\left(\mathrm{X}_{6}\right)$

Jumlah tanggungan keluarga adalah salah satu faktor yang diduga mempengaruhi keputusan petani dalam melakukan konversi lahan sawahnya. Berdasarkan hasil analisis regresi logit variabel jumlah tanggungan keluarga $\left(\mathrm{X}_{6}\right)$ memiliki nilai Sig. sebesar 0,008 atau nilai error sebesar $0,8 \%$. Nilai ini menunjukkan bahwa pada taraf kepercayaan sebesar 95\% variabel jumlah tanggungan keluarga berpengaruh nyata terhadap keputusan petani melakukan konversi lahan sawah. Koefisien hasil yang diperoleh bertanda positif $(+1,066)$ dan nilai odd ratio atau $\operatorname{Exp}(\beta)$ yakni sebesar 2,903. Hal ini berarti jika jumlah tanggungan keluarga bertambah satu orang jiwa, maka peluang petani untuk melakukan konversi lahan meningkat 2,903 kali. Dengan kata lain, peluang petani melakukan konversi lahan sawah adalah sebesar 2,903 kali lebih tinggi dari pada tidak melakukan konversi lahan sawah dengan asumsi variabel lain dalam keadaan konstan.

Hasil regresi logistik berpengaruh karena semakin banyak jumlah tanggungan yang harus ditanggung oleh petani dalam satu keluarga maka kebutuhan akan semakin meningkat pula sehingga petani melakukan keputusan untuk menjual lahan sawahnya. Kebutuhan atas jumlah tanggungan keluarga 
yang harus dipenuhi oleh petani di Kecamatan Kaliwates seperti biaya sekolah anak maupun gaya hidup yang dimiliki khususnya penduduk kota.

3. Saluran Irigasi $\left(\mathrm{X}_{8}\right)$

Saluran irigasi adalah variabel yang menunjukkan ada atau tidaknya saluran irigasi yang terkendala ketersediaan air irigasinya pada sawah petani. Hasil analisis regresi logistik menunjukkan bahwa nilai variabel kendala saluran irigasi memiliki nilai Sig. sebesar 0,001 atau nilai error sebesar $0,1 \%$. Nilai ini menunjukkan bahwa pada taraf kepercayaan sebesar $95 \%$ variabel saluran irigasi berpengaruh nyata terhadap keputusan petani melakukan konversi lahan sawah. Koefisien hasil yang diperoleh bertanda positif $(+3,607)$ dan nilai odd ratio atau $\operatorname{Exp}(\beta)$ yakni sebesar 35,856. Hal ini berarti adanya kendala saluran irigasi akan meningkatkan peluang petani untuk melakukan konversi lahan sebesar 35,856 kali. Dengan kata lain, peluang petani melakukan konversi lahan sawah adalah sebesar 35,856 kali lebih tinggi dari pada tidak melakukan konversi lahan sawah dengan asumsi variabel lain dalam keadaan konstan.

Pertumbuhan penduduk kota yang semakin padat ternyata mendorong para petani untuk beralih ke kawasan sekitar kota. Kepentingan ini diwarnai oleh pihak-pihak pengembang yang semakin gencar mencari lahan untuk melakukan pembangunan untuk menampung para penduduk pendatang. Pemerintah memberikan ijin kepada pengembang untuk melakukan pembangunan perumahan secara kontinyu. Bangunan beton yang menutupi aliran air pada saluran irigasi menyebabkan air tidak mampu masuk dengan lancar untuk mengairi persawahan petani. Sehingga kadang kala pada musim tanam, debit air mengecil yang berakibat pada perebutan kebutuhan air oleh beberapa petani setempat. Ada pula beberapa sawah petani yang mampu mengalirkan air masuk ke persawahan namun tidak dapat membuang air dari persawahan. Sehingga petani tidak bisa mengontrol aliran air yang dibutuhkan untuk tanaman padi mereka. Hal ini menyebabkan petani enggan untuk melakukan penanaman dan menjual lahan sawahnya.

\section{Dampak Konversi Lahan Sawah terhadap Pendapatan Petani di Kecamatan Kaliwates}

Terjadinya konversi lahan sawah di Kecamatan Kaliwates Kabupaten Jember menyebabkan perpindahan lokasi kegiatan usaha tani yang dilakukan oleh petani ke daerah rural (pedesaan). Sebagian besar petani responden yang melakukan konversi lahan sawah, sebelumnya merupakan petani di Kecamatan Kaliwates kemudian membeli lahan sawah di luar Kecamatan Kaliwates seperti di Kecamatan Ajung, Kecamatan Sukorambi, dan Kecamatan Panti. Dampak lain adalah terjadinya pergeseran mata pencaharian utama yang dilakukan petani. Terdapat petani responden yang melakukan konversi lahan, sebelumnya merupakan petani pemilik. Namun akibat konversi lahan pertanian terjadi pergeseran mata 
pencaharian dari sektor pertanian (padi) pendapatan utama dapat dilihat pada Tabel menjadi non sektor pertanian (padi). 10 berikut.

Perubahan mata pencaharian sebagai sumber

Tabel 10. Sumber Pendapatan Utama Petani Setelah Melakukan Konversi Lahan Sawah

\begin{tabular}{lll}
\hline Sumber Pendapatan & Responden & Presentase Responden (Persen) \\
\hline Petani Pemilik Penggarap & 19 & 65,6 \\
Non Usahatani Padi & 1 & 3,4 \\
Buruh Gudang & 1 & 3,4 \\
Buruh Bangunan & 1 & 3,4 \\
Pertokoan & 6 & 20,8 \\
Perdagangan & 1 & 3,4 \\
\hline Jumlah & $\mathbf{2 9}$ & $\mathbf{1 0 0}$ \\
\hline
\end{tabular}

Sumber : Data Primer, 2016 (diolah)

Pendapatan petani pada dasarnya dibedakan menjadi dua macam, yaitu pendapatan usahatani dan pendapatan di luar usahatani. Pendapatan usahatani adalah pendapatan yang diterima dari sektor pertanian (padi). Sedangkan pendapatan di luar usahatani adalah pendapatan yang diperoleh dari luar sektor pertanian (padi).

Tabel 11. Perbandingan Rata-rata Pendapatan Petani Sebelum dan Sesudah Terjadinya Konversi Lahan Sawah

\begin{tabular}{lllllll}
\hline $\begin{array}{l}\text { Rata-rata } \\
\begin{array}{l}\text { Pendapatan } \\
\text { Responden }\end{array}\end{array}$ & \multicolumn{2}{l}{ Usaha Tani } & \multicolumn{2}{l}{ Non Usaha Tani } & \multicolumn{2}{c}{ Rata-rata Pendapatan Total } \\
\cline { 2 - 7 } & Rupiah & \% & Rupiah & \% & Rupiah & \% \\
\hline Sebelum Konversi & 3.038 .091 & 78,1 & 931.897 & 21,9 & 3.888 .520 & 100 \\
Setelah Konversi & 2.581 .190 & 59,1 & 1.786 .207 & 40,9 & 4.367 .397 & 100 \\
\hline Perubahan & -456.901 & & 854.310 & 478.877 & \\
\hline
\end{tabular}

Sumber : Data Primer, 2016 (diolah)

Berdasarkan Tabel 11 menunjukkan bahwa pendapatan baik yang diperoleh dari usahatani padi maupun non usahatani padi mengalami perubahan sebelum dan sesudah konversi lahan sawah. Sebelum melakukan konversi lahan sawah, sebesar 78,1 persen pendapatan diperoleh dari usahatani dan sebesar 21,9 persen pendapatan diperoleh dari non usahatani. Setelah melakukan

Pendapatan sebelum dan sesudah konversi lahan selanjutnya diselisihkan. Hasil selisih tersebut dapat melihat pengaruh konversi lahan pertanian terhadap pendapatan petani setempat. Perhitungan rata-rata pendapatan yang diperoleh petani sebelum dan sesudah melakukan konversi lahan sawah dapat dilihat pada Tabel 11.

konversi lahan sawah, sebesar 59,1 persen pendapatan diperoleh dari usahatani dan sebesar 40,9 persen pendapatan diperoleh dari non usahatani. Hal ini menunjukkan adanya pergeseran struktur pendapatan petani dari yang berstruktur agraris ke non agraris. Pendapatan yang berasal dari luar usahatani mengalami peningkatan lebih tinggi setelah melakukan konversi lahan sawah. 
Pendapatan total rata-rata petani responden (usahatani dan non usahatani) sebelum dan sesudah konversi lahan sawah terjadi perubahan dari Rp. 3.888.520 menjadi Rp. 4.367.397. Perbedaan yang signifikan atau tidak dapat dilihat dari analisis uji beda rata-rata secara statistik. Uji beda rata-rata yang digunakan adalah uji $T$-test untuk

Tabel 12. Uji Beda Rata-Rata (Uji-T) Antara Pendapatan Petani Sebelum dan Sesudah Melakukan Konversi Lahan Sawah

\begin{tabular}{llllllll}
\hline Jenis Petani & N & $\begin{array}{l}\text { Rata-rata } \\
\text { Bulan) }\end{array}$ & Pendapatan & (Per & Sig. & t-hitung & t-tabel \\
\hline Sebelum Konversi & 29 & 3.888 .520 & & & 0,154 & 1,464 & 2,048 \\
Setelah Konversi & 29 & 4.367 .397 & & & & \\
\hline
\end{tabular}

Sumber : Data Primer, 2016 (diolah)

Berdasarkan pada Tabel 12, diperoleh $\mathrm{t}$ hitung 1,464 dengan signifikansi0,154. Sedangkan berdasarkan tabel uji $\mathrm{t}$ didapatkan nilai t-tabel adalah 2,048. Nilai t-hitung kurang dari t-tabel $(1,464<2,048)$ dan nilai signifikansi 0,154 lebih dari $0,050(0,154>0,050)$. Berdasarkan kriteria pengambilan keputusan yang ditetapkan jika $\mathrm{t}_{0}<\mathrm{t} \alpha$, maka $\mathrm{H}_{0}$ diterima yang berarti tidak terdapat perbedaan pendapatan petani sebelum dan sesudah konversi lahan sawah. Hal ini menunjukkan bahwa secara statistik tidak terdapat perbedaan yang nyata dan signifikan antara pendapatan petani sebelum melakukan konversi lahan sawah dan petani setelah melakukan konversi lahan sawah.

Hasil uji statistik t-test menunjukkan bahwa terdapat peningkatan rata-rata pendapatan total petani, namun peningkatan tersebut tidak signifikan. Sebagian besar petani yang melakukan konversi lahan sawah mengalokasikan hasil pendapatan dengan sampel terikat (dependent sample t-test) karena pengukuran analisa hasil pendapatan dilakukan pada petani yang sama yaitu petani yang melakukan konversi lahan sawah. Hasil uji beda rata-rata antara petani sebelum dan sesudah melakukan konversi lahan sawah dapat dilihat pada Tabel 12 berikut. 
Kecamatan Kaliwates. Tingginya biaya tersebut dikarenakan ada tambahan biaya untuk membayar orang sebagai kepercayaan pemilik lahan sawah.

Investasi petani lainnya adalah membuka atau mengembangkan di sektor non usaha tani (padi). Ada tipe petani yang melakukan pilihan kegiatan setelah mengkonversi lahan sawahnya. Pertama, ada petani yang melakukan konversi lahan sawah untuk mengembangkan usaha yang sudah ada seperti usaha showroom motor, jasa persewaan, angkutan, dan perdagangan. Kedua, ada petani yang membuka usaha baru di bidang non pertanian seperti membuka meubel, usaha perdagangan, dan pertokoan. Ketiga, ada pula petani yang tidak membuka usaha di bidang non usahatani. Berdasarkan hal tersebut, tidak semua petani menggunakan sisa hasil konversi lahan sawah untuk mengembangkan usaha di luar usaha taninya. Konversi lahan yang mereka lakukan kadangkala bukan hanya untuk mencari sumber penghasilan yang dapat menyokong kehidupan mereka melainkan kini para petani mengamalkan budaya konsumtif. Beberapa petani melakukan konversi lahan sawah untuk memenuhi kebutuhan keluarga, menunaikan ibadah haji, membayar hutang, dan membeli kendaraan mewah. Sehingga pengembangan usaha yang dijalankan tidak menghasilkan pendapatan yang optimal.

\section{KESIMPULAN}

Berdasarkan hasil penelitian dan pembahasan yang telah dilakukan dapat ditarik kesimpulan, sebagai berikut: 1) Laju konversi lahan sawah di Kecamatan Kaliwates Kabupaten Jember mengalami penyusutan. Selama kurun waktu 2006-2015 laju konversi lahan sawah sebesar 4,359\% atau seluas 38,48 ha per tahunnya; 2) Faktorfaktor yang mempengaruhi keputusan petani melakukan konversi lahan sawah di Kecamatan Kaliwates Kabupaten Jember adalah harga lahan, jumlah tanggungan keluarga, dan saluran air irigasi; 3) Dampak konversi lahan sawah terhadap pendapatan petani di Kecamatan Kaliwates Kabupaten Jember adalah tidak terdapat perbedaan pendapatan yang nyata antara petani sebelum dan sesudah konversi lahan sawah. Rata-rata pendapatan total petani sebelum dan sesudah konversi lahan sawah terjadi perubahan dari Rp. 3.888.520 menjadi Rp. 4.367.397.

Berdasarkan hasil penelitian dankesimpulan, beberapa saran direkomendasikan sebagai bahan pertimbangan yaitu sebagai berikut: 1) Pemerintah harus mendorong pihak developer untuk tetap menjaga keberadaan saluran irigasi, sehingga tidak mengganggu lahan persawahan yang belum terkonversi. Kondisi tersebut pada akhirnya akan membuat petani tidak tertarik untuk melakukan konversi lahan. 2) Pemerintah perlu meninjau ulang kebijakan perizinan pembangunan yang dilakukan di lahan pertanian khususnya untuk keperluan perumahan yang banyak terjadi di Kecamatan Kaliwates Kabupaten Jember. Kebijakan Rencana Tata Ruang Wilayah (RTRW) perlu diperkuat sehingga mampu 
mengendalikan konversi lahan sawah. Selain itu perlu diterapkannya suatu peraturan tentang Perlindungan Lahan Pangan Produktif di Kabupaten Jember agar dapat melindungi lahan pertanian serta memberikan sanksi secara progresif bagi pelanggar.

\section{DAFTAR PUSTAKA}

Agustina Ina dan Robbinov Dwi. 2016. Kajian Alih Fungsi Lahan Pertanian Terhadap Swasembada Beras di Kabupaten Bekasi. Prosiding Perencanaan Wilayah dan Kota. Vol 2 No 1. Universitas Islam Bandung: Bandung.

Badan Pusat Statistik Kabupaten Jember, 2015. Statistik Daerah Kabupaten Jember Tahun 2015. Jember : Badan Pusat Statistik.
Gani dan Siti Amalia. 2015. Alat Analisis Data : Aplikasi Statistik untuk Penelitian Bidang Ekonomi dan Sosial. Yogyakarta : ANDI.

Irawan, Bambang. 2008. Meningkatkan Efektifitas Kebijakan Konversi Lahan. Forum Penelitian Agro Ekonomi Vol 26 No 2. Balai Pengkajian Teknologi Pertanian : Lampung.

Soetriono, Anik Suwadari, dan Rijanto, 2006. Pengantar Ilmu Pertanian. Malang : Bayumedia.

Sugiyono, 2014. Metode Penelitian Kuantitatif Kualitatif dan $R \& D$. Bandung: Alfabeta. 